\title{
Psychological, emotional and physical experiences of hospitalized children
}

\author{
Ami Rokach ${ }^{1,2 *}$ \\ ${ }^{1}$ York University, Toronto, Canada \\ ${ }^{2}$ Walden University, MN, USA
}

Being sick and hospitalized is not an easy or a regular occurrence, and may even be terrifying, traumatic, to the child and/or her parents. This article explores this experience from the child's point of view, in an attempt to highlight -for the medical community and the child's caregivers - what the child needs while in the hospital.

\begin{abstract}
The modern hospital environment is geared towards providing a safe and healing environment for those afflicted with a variety of illnesses. In the health care system, patients receive the most contemporary care available. They benefit from modern technology in the hands of professional and dedicated doctors and staff with the most updated understanding of the human body and various treatments available [1]. The experience of illness and hospitalisation nonetheless exerts a great deal of psychological distress, one of the most distressful events people might actually experience in their life time [2]. Being admitted to the hospital, there is a serious disruption in one's life, in her routines, and they must now start to perceive the hospital as their home for as long as they remain there as patients. Additionally, the patients, as well as those individuals who are usually responsible for the health of the patient, often live in a state of constant worry about the patient's condition, and are forced to instill their complete faith in the medical professionals at the hospital to provide them with appropriate care that will hopefully lead to their healing $[3,4]$. From the outset, we know that illness is a major stressor in one's life [5]. Various symptoms of the illness put the body into a state of continuous stress, which may include fatigue, immobility and even loss of bodily functions and control [6]. Being hospitalised, individuals may experience a wide range of shortterm as well as long term consequences [7]. It is not only the physical suffering and distress that exerts stress on the body, but also factors that negatively affect the patient's psychological state [8].
\end{abstract}

\section{Experience of children in hospitals}

As discussed, the experience of being hospitalised is usually an anxiety-provoking and even traumatic experience, especially for children. Children are particularly prone to the adverse effects of being ill, and their hospitalisation is a stressful event with potential untoward consequences for children and their families [9]. In a sense, for children 'the hospital is like a foreign country to whose customs, language and schedules they must learn to adapt' [10]. Due to cognitive and emotional limitations and dependence on others, they are particularly vulnerable to stresses involved in adapting to their condition of illness and hospitalisation [11].

Consequently, eliciting hospitalised children's view and documenting their experiences appears to be an essential task. A considerable body of research on the effects of paediatric hospitalisation has been conducted since the 1950s, and remains a vital area of inquiry to this date $[4,12,13]$. All those concerned with the welfare of children aim to minimise the social and emotional consequences of childhood hospitalisation [14]. When children are scared, tired or in pain, they are particularly dependent on the safe and stable environment of their home and on the support and love of their family members in order to be able to cope and feel strength and capable [15]. For children, this is not only a subjective need, but also a vital necessity. While growing up, children are greatly dependent on their parents for everyday functioning and well-being, but especially when they become ill, they need their families' support more than ever, since their limited coping skills and emotional resources are not 'designed' to handle the tremendous amount of physical and emotional stress on them during hospitalization [16]. When children's illness is serious enough to warrant their confinement to hospital, they often report feeling lonely and scared, as they are taken away from the safe and empathetic environment of their home and instead are forced to reside in an unfamiliar, intimidating and uncomfortable environment.

For this reason, the process of treatment and hospitalisation may produce a tremendous amount of stress in addition to that which is precipitated by the illness itself. Young children are particularly affected and are more likely to associate their experienced discomfort of illness and hospitalisation to understandable notions such as being away from home, and being separated from parents [17].

Recent empirical data highlights that adverse effects of hospitalisation on children, have been found to be stronger when parents are not present, or when parents are highly anxious and were not able to calmly respond to them [18]. Illness and hospitalisation are

Correspondence to: Ami Rokach, Psychology Department, York University, 104 Combe Avenue, Toronto, Ontario, Canada, E-mail: arokach@yorku.ca

Key words: children, sick children, illness, hospitalization, medical staff, caregivers Received: March 03, 2016; Accepted: March 23, 2016; Published: March 26, 2016 
traumatic, anxiety provoking and can lead to transient or long-term behavioural and psychological difficulties in children [19]. Estimates of the incidence of emotional problems resulting from hospital experience have been reported to vary from $10 \%$ to $30 \%$ for severe psychological distress to as much as $90 \%$ for slight emotional upset in hospitalised children [20].

Research indicates that the implications of hospitalization are often present quite strongly immediately after the hospitalisation discharge, which generally subdues soon afterwards [21]. Children, due to their limited maturity and life experience, cannot adequately infer the true causes of their hospitalisation, and might instead interpret their hospitalisation as a punishment for something they have done wrong. It has been argued that hospitalisation can be a life crisis for children, which might further highlight and aggravate their experience of fear, loneliness and frustration. Arguably for some children, this is a crisis that if not mastered properly may result in blocks or distortion in their process of development, and might be exceedingly damaging to their sense of identity and self-esteem [22,23].

While most of us do not enjoy getting injections, research on paediatric hospitalisation has shown that procedures involving needles and injection, or blood tests and transfusions often evoke a very distressing and fearful reaction in young children [16,24,25]. Also, it is often very difficult for children to feel confident and reassured that the treatment they receive is actually for the purpose of helping them and making them feel better in the long run. This fear might then lead to uncooperativeness with medical procedures [19]. One of the most distressing event for children is undergoing a surgical procedure, which they often perceive as assaultive and mutilative, even if it is but a minor and routine procedure $[19,26]$. Research has shown that for children and adolescent patients, heightened levels of preoperative anxiety increase the possibility of negative psychological consequences throughout their recovery, such as continuing anxiety, separation anxiety, problems with sleep, nightmares, irritability and aggressiveness [8].

The most difficult period of hospitalisation may be near the beginning of the experience, when children, often unexpectedly and unwillingly, have to encounter these fearful and painful procedures and treatments for the first time. It has been observed that hospitalised children are often in a state of waiting and increased vigilance which results in dragging of time [27]. Being confined to bed or being socially restricted can seem like an unending state of imprisonment to children, regardless of the length of stay.

Chronically ill children often suffer from additional anxiety and long-term adjustment problems, as they often fall behind of their normal routines and activities which help them in developing behavioural and emotional competencies further in life. For example, they often express sadness and anxiety over missing out on school, and having limited chance of socialising with their friends and peers, or being involved in their family life and interactions with their parents and siblings [15].

The hospitalised children's level of physical activities is inherently limited, and thus their means for making sense of the world around them are threatened [28]. As can be seen in any paediatric hospital, hospitalised children tend to engage in less play activity, and when they do engage, their play is characterised by repetitive, solitary themes. This is unfortunate and even damaging since an important coping mechanism for children with a stressful environment such as the hospital is play, which helps in alleviating their anxiety and increasing their adjustment [29]. Worry about the loss of bodily functions and fear of disfigurement are particularly prevalent for children. The experience of feeling different and the anticipation of a distorted body image [in case of having gone through a serious and disfiguring surgery], may further aggregate the anxiety of hospitalised youth while recovering in the hospital, and can even pose a threat to their identity formation and sense of self [19].

To conclude, hospitalized children are commonly confused, frightened, and in need of support, reassurance, explanation of what they will be exposed to [in a manner that fits their level of maturity], and mostly, they need to be recognized as 'little people' who are yearning to be treated not just as 'bodies' but as humans with emotions, pain, illness, and concerns.

It is suggested that health care professionals, such as physicians, nurses, psychologists and social workers who are affiliated with hospitals need to be aware of the psychological and emotional needs of their clients, particularly those of children. In particular, paediatric hospitals must go beyond a narrow focus of the medical aspect of treating children's illnesses, and improve the implications of the hospitalisation's distress on children by providing age-appropriate communication, support and empathy of the medical and psychological staff, and devise means of interventions for those children who display marked signs of distress. For instance, the Sick Kids Hospital, in Toronto Canada, created a theatre for hospitalized children, where their fears, and in case of physical effects of the illness or surgery, their concerns of being different are addressed, and children are taught that different is not a weakness or a negative label, but is an individual difference to be respected [4]. Additionally, children's hospitals have introduced programs of acquainting the children with the hospitals, its routines, anticipated surgery that the children may need to undergo, and involving their parents in the process [30,31].

\section{References}

1. Rollins JA (2004) Evidence-based hospital design improves health care outcomes for patients, families, and staff. Pediatr Nurs 30: 338-339. [Crossref]

2. Hughes BM (2001) Psychology, hospitalization and some thoughts on medical training. European Journal of Psychotherapy and Counselling 4: 7-26.

3. Paul F, Rattray J (2008) Short- and long-term impact of critical illness on relatives: literature review. J Adv Nurs 62: 276-292. [Crossref]

4. Rokach A, Matalon R (2007) 'Tails' - A fairy tale on furry tails: A 15-year theatre experience for hospitalized children created by health professionals. Paediatr Child Health 12: 301-304. [Crossref]

5. Sellick SM, Edwardson AD (2007) Screening new cancer patients for psychological distress using the hospital anxiety and depression scale. Psychooncology 16: 534-542. [Crossref]

6. Rowe MA (1996) The impact of internal and external resources on functional outcomes in chronic illness. Res Nurs Health 19: 485-497. [Crossref]

7. Thomas LH, Bond S (1996) Measuring patients' satisfaction with nursing: 1990-1994 $J$ Adv Nurs 23: 747-756. [Crossref]

8. Rattray JE, Johnston M, Wildsmith JA (2005) Predictors of emotional outcomes of intensive care. Anaesthesia 60: 1085-1092. [Crossref]

9. Kennedy C, Kools S, Kong SK, Chen JL, Franck L, et al. (2004) Behavioural, emotional and family functioning of hospitalized children in China and Hong Kong. Int Nurs Rev 51: 34-46. [Crossref]

10. Hall D (1987) Social and psychological care before and during hospitalization. Soc Sci Med 25: 721-732. [Crossref]

11. Sartain SA, Clarke CL, Heyman R (2000) Hearing the voices of children with chronic illness. J Adv Nurs 32: 913-921. [Crossref]

12. Gonzalez-Gil F, Jenaro C, Gomez-Vela M, Flores N (2008) Perceived quality of life and health of hospitalized children. Child Indicators Research 1: 198-220. 
13. Prugh DG, Staub EM, Sands HH, Kirschbaum RM, Lenihan EA (1953) A study of the emotional reactions of children and families to hospitalization and illness. Am J Orthopsychiatry 23: 70-106. [Crossref]

14. Mah JK, Tough S, Fung T, Douglas-England K, Verhoef M (2006) Adolescent quality of life and satisfaction with care. J Adolesc Health 38: 607. [Crossref]

15. Angström-Brännström C, Norberg A, Jansson L (2008) Narratives of children with chronic illness about being comforted. J Pediatr Nurs 23: 310-316. [Crossref]

16. Boyd JR, Hunsberger M (1998) Chronically ill children coping with repeated hospitalizations: their perceptions and suggested interventions. J Pediatr Nurs 13:330342. [Crossref]

17. Simeonsson RJ, Buckley L, Monson L (1993) Conception of illness causality in hospitalized children. In: Roberts MC, et al. (Eds.), Readings in pediatric psychology (pp. 173-180). New York: Plenum Press.

18. Shields L (2001) A review of the literature from developed and developing countries relating to the effects of hospitalization on children and parents. Int Nurs Rev 48: 2937. [Crossref]

19. Hägglöf B (1999) Psychological reaction by children of various ages to hospital care and invasive procedures. Acta Paediatr Suppl 88: 72-78. [Crossref]

20. Yap JN (1988) The effects of hospitalization and surgery on children: A critical review. Journal of Applied Developmental Psychology 9: 349-358.

21. Thompson RH, Vernon DT (1993) Research on children's behaviour after hospitalization: A review and synthesis. J Dev Behav Pediatr 1: 28-35. [Crossref]
22. Goslin ER (1978) Hospitalization as a life crisis for the preschool child: a critical review. J Community Health 3: 321-346. [Crossref]

23. Yeh CH (2001) Adaptation in children with cancer: research with Roy's model. Nurs Sci $Q$ 14: 141-148. [Crossref]

24. Kortesluoma RL, Nikkonen M (2006) 'The most disgusting ever': children's pain descriptions and views of the purpose of pain. $J$ Child Health Care 10: 213-227. [Crossref]

25. Woodgate R, Kristjanson LJ (1996) My hurts": Hospitalized young children's perceptions of acute pain. J Pediatr Nurs Qual Health Res 6: 184-201.

26. Sheridan MS (1975) Children's feelings about the hospital. Soc Work Health Care 1: 65-70. [Crossref]

27. Holloway IM, Smith P, Warren J (1998) Time in hospital. J Clin Nurs 7: 460-466. [Crossref]

28. Haiat H, Bar-Mor G, Shochat M (2003) The world of the child: a world of play even in the hospital. J Pediatr Nurs 18: 209-214. [Crossref]

29. Gariépy N, Howe N (2003) The therapeutic power of play: examining the play of young children with leukaemia. Child Care Health Dev 29: 523-537. [Crossref]

30. Williams AM, Irurita VF (2005) Enhancing the therapeutic potential of hospital environments by increasing the personal control and emotional comfort of hospitalized patients. Appl Nurs Res 18: 22-28. [Crossref]

31. http://www.sickkids.ca

Copyright: (C2016 Rokach A. This is an open-access article distributed under the terms of the Creative Commons Attribution License, which permits unrestricted use, distribution, and reproduction in any medium, provided the original author and source are credited. 